\title{
The Role of Conventional and Molecular Techniques for Chickpea (Cicer arietinum L) Improvement
}

\author{
Tibebu Belete* \\ Department of Plant Sciences and Horticulture, Samara University, Ethiopiao
}

Submission: June 30, 2018; Published: August 15, 2018

*Corresponding author: Tibebu Belete, College of Dry land Agriculture, Department of Plant Sciences and Horticulture, Samara University, P.O. Box 132, Samara, Ethiopia, Tel: +251911958252; E-mail: tibebubelet@su.edu.et

\begin{abstract}
Chickpea yield reduction was resulted from several biotic and abiotic factors including susceptibility of landraces to frost, drought, water logging and poor cultural practices; low or no protection measures against weeds, diseases and insect pests and inherently low grain yielding potential of landraces. Lack of requisite genetic variation in the cultivated species has necessitated systematic collection, documentation and evaluation of wild Cicer species for use in chickpea variety improvement programmes. Various studies have clearly indicated the possibility of transferring resistance genes and desirable co-adapted gene complexes from unexploited wild annual species to the cultivated species. At this juncture, the valuable genetic resources present in the primary gene pool can be successfully utilized in plant breeding programmes for genetic enhancement of chickpea. However, most of the wild species possessing high degree of resistance to multiple stresses are present in the secondary and tertiary gene pools where hybridization with the cultivated species is often limited by reproductive barriers. Gene introgression from the wild species can be monitored effectively with the use of molecular markers, which will expedite the transfer of agronomically important traits into desirable genetic backgrounds for the development of varieties with durable resistance through marker assisted selection.
\end{abstract}

Keywords: Chickpea; Genetic Diversity; Molecular Markers; Marker Assisted Selection; Various studies; Cultivated species; Plant breeding; Hybridization; Wild species; Climate; Pathogens; Predators; Competitors; Strategic value; Conservation; Populations; Morphological; Fungicides; Ethiopia; Technology; Isoenzyme

Abbreviations: RFLP: Restriction Fragment Length Polymorphism; RAPD: Random Amplified Polymorphic DNA; AFLP: Amplified Fragment Length Polymorphism; Dart: Diversity Array Technology; SNPs: Single Nucleotide Polymorphisms; SSR: Simple Sequence Repeats

\section{Introduction}

Crops improvement depends on the availability of gene for better agronomic traits, disease resistance, earliness and high yield [1]. For this, characterization of genetic variability of a population is required since genetic variation within population and between species determines the rate of adaptive evolution and response to traditional crop improvement [2]. Genetic diversity is a raw material for evolution, thus enabling populations of species to survive, evolve and adapt to resist longterm changes in the environment. This is very important in the plant breeding strategies for developing high yielding varieties and for maintaining the productivity of such varieties through introduction of genes for resistance to disease, insect pests and other abiotic factor [3]. Genetic diversity of domestic species allows people to act as agents of selection and develop different forms of the same species for a variety of purposes, including enabling the producers to grow the same species in different environments, each with a different requirement of climate, pathogens, predators, competitors etc [2]. Differences within and between plants can be a strategic value to conservation as they provide a clear justification for protecting a species across its entire geographic range and all the subspecies of major populations.

Genetic variability has been the main driving force used by man to meet not only its food needs but also to produce better cultivars. In the early days, naturally occurring mutations were the main source of new alleles for obtaining more adapted materials. This process led to rapid fixation of traits in elite gene pools and it became more difficult to select for subtle differences in naturally occurring populations. Mendel's work set up the principles and a new scenario for hybridization programs, through which plant breeders could generate genetic variability. However, due to linkages there was a need to look for ways to follow up and select for desirable traits in segregating populations.

Starting in the 1920's, many researchers used morphological markers with some degree of success mainly in maize improvement program. Nevertheless, this kind of markers 
had serious drawbacks that limited its usefulness, especially in terms of its low number and its expression being affected by environmental conditions. In the 1980's, the advent of DNA markers made it possible to develop genetic maps in any crop, and to apply them to get a better understanding of genetic variation in many gene pools.

Therefore, characterizations of the different traits via morphological, biochemical and DNA markers for their genetic variation will help plant breeder to utilize them in the chickpea improvement.

\section{Role of conventional breeding technique in chickpea improvement}

Plant breeding has been one of the most successful technologies developed in modern agriculture all over the world because its methods are adaptable to various production schemes, require inexpensive inputs and the products have pervasive social benefits. For most grain crops, yields have increased continuously since the 1930 s and nearly $50 \%$ of the gains may be attributed to the enhanced genetic potential of the cultivars. Besides increased productivity, plant breeding has contributed to remarkable transformations in quality, growth habits and use and adaptation. Though few endeavors were less successful, the genetic modifications of crop species achieved through plant breeding have been very positive and important [4]

To improve the world position of chickpea, the area under chickpea cultivation needs to be expanded as it is tolerant to dry conditions and can be used as fallow replacements in many areas of the arid regions especially in Africa and America, where area of the crop is small, but yield is much higher than in Asia. Introduction of higher input use is yet another approach to increase the chickpea production as practiced in European countries [5].

Selection of various appropriate traits is an important criterion to improve the crop production. In chickpea, variation for growth duration, yield, biomass and disease resistance are recorded. Seed mass is another highly heritable and important yield component in chickpea, which can be used effectively as an indirect selection criterion for improving seed yield [6]. Development of new plant types like erect/upright plant with few branches instead of traditional bushy plant canopy for better light interception and canopy air exchange and; tall plant height for better competition against weeds and suitability for mechanical harvesting can be manipulated to increase the yield potential. Seed cost can be reduced to improve the production as the costs are very high because of strong demand and short supply. Also, regular application of fertilizers, pesticides and fungicides will improve the yield of this legume crop. Apart from these conventional approaches, productivity enhancement in chickpea can be achieved by amalgamation of classical breeding techniques and the biotechnological advances especially in developing countries. This will also help to enhance profitability of chickpea, particularly in the major chickpea growing countries where yields are low.

\section{Genetic markers and their applications}

Genetic marker can be defined as a specific gene that produces a recognizable trait and can be used in family or population studies. There are different genetic markers for evaluating genetic variation: morphological, biochemical and DNA markers [7]. Using such markers, genetic variation studies were conducted on different crops so far, including cereals, pulses, horticultural crops and fruits.

\section{Morphological markers}

Morphological markers are a classical method to distinguish variation based on the observation of the external morphological differences (phenotypic characters) such as flower color, seed shape, growth habits or pigmentation. They can be scored quickly without specialized laboratory equipment, but their expression occurs at specific growth stages. The possibility of analyzing only a limited number of markers in a single population limits their use in breeding programs. Moreover, they are generally dominant traits, and they often exhibit epistatic interactions with other genetic traits and are influenced by environmental factors [8].

Dulloo et al. [9] reported that morphological traits and statistical analysis of quantitative agro-morphological traits along with ecogeographic information are used in estimating genetic diversity. Morphological studies of Ethiopian chickpea landraces showed that there is considerable variability with and between chickpea population [10]. The author indicated that there is a variation of chickpea in different regions and altitude. This report also indicated high significance difference between populations for most of the quantitative morphological traits except for days to maturity, grain yield/plot, biological yield and harvest index. Mengesha [11] also indicated high variation of chickpea in Shewa; medium variation in Gonder, Gojam and Tigray. Kumar et al. [12] also reported high coefficient of variation for biological yield followed by grain yield, pods/plant and effective branches. They also indicated low of variation for days to flower, plant height, and seeds/pod. A Research report on the Ethiopian chickpea landraces also showed low variation in traits such as days to flowering and maturity and plant height [10]. Some morphological traits are confined to certain areas [13] that resulted from homologous mutation. On chickpea there was showing that black seeded chickpeas are mainly confined in Ethiopia and absent in Turkish, Afganstan and Caucasus [13].

Although morphological markers are technically simple, they have several limitations. Discrete morphological traits, which show high heritability, are limited in number, each being governed by a few genes and hence, cover only a small portion of the genome. Quantitative traits are influenced by environmental factors, implying that these traits show continuous variation. This results in low heritability and high genotype by environment 
interactions that make it difficult to determine genetic variation accurately.

There are various studies on heritability and genetic gain for different morphology traits of chickpea. High value of genetic gain and heritability was for seed weight, number of pods and seed yield [14], seed index, number of seeds/plant and time to flowering [15]. High heritability coupled with high expected genetic gain may result due to high additive gene effects and thus selection applied on such traits lead to yield improvement [16]. On the contrary, there was low expected genetic gain for days to flowering and seeds/pod [14], plant height, number of pods, number of pods and yield/plant [15]. In such traits, most of the variation is environmental thus leading to low heritability and low expected genetic gains from selections and eventually results in low progress of selection. The usefulness of estimates of heritability and expected genetic advance from selection depends on their repeatability, which is found to vary with methods of estimation, cross, generation, sample size, and the environment [17]. These authors described that for most characters the genetic gain from selection were low that might be due to restricted genetic variation. Association among these morphological traits are useful for selecting genotypes possessing groups of desired characters although such correlation coefficients could vary with genotypes studied and the environment where the test is carried out [18]. Among the seed yield components effective plant height and effective pods/ plant are important for seed yield improvement [19].

\section{Molecular markers and biochemical markers (isozymes)}

Biochemical and DNA markers are developed to overcome limitations of morphological data although it does not mean that any of the biochemical or molecular techniques or both replace morphological marker. A variety of molecular techniques are available for detecting genetic diversity and relationships within and among cultivated crops including chickpea. According to Sharman et al. [20] molecular markers have several advantages over morphological markers. These include numerous markers that can be identified in a single breeding population with relatively large number of alleles available for one marker, most of them exhibiting as co-dominant mode of inheritance. They are generally silent in their effects on phenotypes. The environments do not influence them, and they can be scored at a very early development stage allowing early population screening. A number of molecular markers including isozyme, Restriction Fragment Length Polymorphism (RFLP), Random Amplified Polymorphic DNA (RAPD), Amplified Fragment Length Polymorphism (AFLP), Diversity Array Technology (DArt), Single Nucleotide Polymorphisms (SNPs) and Simple Sequence Repeats (SSR) etc are available for different uses at different time. Different research findings showed that these different molecular markers have been reliably used in:

a. Cultivars identification,

b. Diversity analysis, c. Construction of genetic maps,

d. Tagging agronomically important genes,

e. Prediction of hybrids,

f. Germplasm management,

g. Assessment of genetic purity of inbred lines and varieties,

h. Selection of recurrent parental genome in backcrosses and segregating generations thereby reducing the number of generations required in producing inbred lines,

i. Paternity analysis in perennial and tree crops,

j. Monitoring genetic stability of germplasm conserved in the form of seeds and tissues and their detection of somaclonal variants,

k. Screening of duplicate accessions in gene bank etc [21].

Chickpea breeding, especially resistance breeding will also benefit from the application of molecular markers for development of superior resistant cultivars [3].

In general, biochemical markers include variants in various biochemicals including physiochemical variations of bio-molecules such as storage (seed) proteins, carbohydrates and lipids, and as such biochemical markers are generally intermediate between morphological and DNA markers since they are often the intermediate results of gene expressions. Among the biochemical markers, the most widely used genetic markers are the many protein variants of an enzyme referred to as isozymes, having slightly different molecular structures and arising from different alleles. Isozymes, or otherwise termed "allozymes" when referring to the corresponding loci of the isozymes, can be resolved by electrophoresis and are very useful genetic markers. The alleles of most isozyme markers segregate in a co-dominant manner and rarely show epistatic interactions, which allows accumulation of many polymorphic isozyme loci in a single F2 population and increases the efficiency of gene mapping. Once the map locations of isozyme genes are known, they can be used efficiently as biochemical markers to map other genes for morphological, physiological and Phyto pathological traits [22].

Isoenzyme is popular biochemical markers that used in diversity analysis of different plants [9]. It possesses several positive attributes for use in genetic analysis: its electrophoresis could provide relatively quicker and easier access to be used as reliable biochemical marker; only small amounts of tissues are required; alleles exhibit simple Mendelian inheritance and co-dominate expression in most cases and comparisons of homologous loci across populations and related species are straightforward [23]. Isoenzyme electrophoresis of chickpea had revealed insufficient polymorphism particularly in cultivated chickpea as a result of a narrow genetic variability [10]. However, as Winter [3] reviewed by citing Kazan et al. [24], showed that 
there is already developed map based on the morphological and isoenzyme markers for crosses between C. arietinum, C. reticulum and C. echinospermum, in to which a DNA marker map could be integrated.

Random Amplified Polymorphic DNA (RAPD) also represents a source of genetic variation that is easy to access, very quick, efficient in the production of DNA polymorphism [25]. It provides supplementary information to morphological or agronomic characters. It can detect misclassification of accessions in collections obtained [26]. Its protocol is ready for use in breeding, for registration, control of distribution of commercial cultivars, the control of seed purity, categorizing accessions in germplasm stock, determining the relation between population and creating subsets of genetically closer populations, reorganizing and comparing germplasm collections characterized by morphological descriptors, creating subsets within the same morphological group and quantifying their variability [21]. Furthermore, the number of potential RAPD markers is higher in magnitude than for the morphological or isozyme markers, leading to a much higher level of marker saturation on genetic maps. RAPD analysis was used in diversity analysis of different plants such as coffee, cereals [27], horticulture [28]. RAPD was also used in study the relationships among annual Cicer species and revealed existence of genetic relationships among these species [29]. However, Hardys et al. [30] identified the following drawback of RAPD. First, there is a problem of dominant allelic expression and the associated problem of having to assume two alleles per locus.

As a result, RAPD provides less genetic information on a per locus basis than co-dominant loci when applied to questions of population genetic structure, paternity, outcrossing rates or hybridization. Second, a primer size determines the degree of specificity in genome scanning. A primer having short length may amplify unreasonably large number of sequences and those larger primers will amplify too few sequences to be routinely informative. Increasing primer length beyond certain point may also increase nonspecific primer annealing; consequently, increasing the probability of random non reproducible amplification patterns. Third, the assumption of the use of RAPD techniques is that the amplified fragments are unique. Eluting individual PCR products from gels and reprobing the products via southern analysis can easily detect the co-migration. Fourth, the principal limitation of RAPD arises from its sensitivity to the reaction condition and a slight change in the reaction condition may affect the reproducibility of the amplification. Fifth, there is non-Mendelian inheritance indicating that RAPD artifact that may lead to misleading results in some applications. Sixth, unlike other methods, the nature of the sampling regions and differences in band intensity in RAPD is poorly understood. Finally, there is a general prevalence of non-parental artificial bands that could reduce the utility of RAPD in molecular genetics, especially in paternity studies.
In general, multivariate analysis performed on sets of traits (agro/morphological, biochemical and agro/morphological plus biochemical traits) showed that the relation between agro/ morphological and biochemical descriptors were low. The two markers reflect different patterns of diversity even though neither of them identifies unique phenotypes. Gepts [31] also pointed out that results from morphological, biochemical and DNA trait studies are not always correlated and this discrepancy may be attributed to possible selective effects that more likely to be associated with morphological traits than molecular markers. Such results imply no single method (biochemical, morphological or DNA markers) is adequate for assessing genetic variation in germplasm as these different methods sample genetic variation at different levels and hence, differ in their power of genetic resolution as well as the quality of information. Because of their high polymorphism and high resolution, DNA markers should be considered only as complementary to morphological and biochemical characterization and analysis [32].

\section{Assessment of genetic diversity and its importance in chickpea improvement}

The study on genetic diversity of species is emphasized because modern breeding practices have narrowed the genetic diversity of cultivated crops. This reduction in genetic diversity could severely limit future breeding programs for adaptive traits such as resistance to biotic and abiotic stresses and reduce stability of crop yields [33]. Pedigree information or morphological characteristics [34], qualitative and quantitative traits, biochemical and isozyme markers [35], seed storage protein analysis [36], and DNA based markers have been exploited to estimate the genetic diversity in various crops.

The main advantages of using molecular markers are that they measure the genetic diversity at DNA level, can account for the effects of selection, are environment-independent, and are available in an enormous number. Further, invention of PCR technology and its technical simplicity to detect even single-base pair difference facilitated its use in the analysis of phylogenetic relationships, cultivar identification, genetic diversity, parentage determination and marker-assisted selection in several plant genera. Although extensive studies were carried on phylogenetic relationship in Cicer species using allozymes [37] and seed storage proteins [29], very few reports are available at the DNA level except RFLP analysis [38], RAPD studies [29], allelic variation studies at a microsatellite locus [39] and STMS analysis [40]. Hence, the enormous potential of molecular markers can be further explored in chickpea for genetic relationship studies, genome mapping and indirect selection (marker assisted selection), gene tagging of qualitative and quantitative traits, marker-aided prediction and improvement of hybrid vigor.

Knowledge of genetic diversity and relatedness in the germplasm of both cultivated and wild species is a prerequisite for their better utilization in crop improvement programmes. 
Genetic markers have been widely used to detect genetic variation at individual gene loci (alleles of a gene), among several loci or gene combinations, between individual plants within plant populations, or between populations. In chickpea, as in most other plant species and organisms, phenotypic or morphological traits, isozymes and other biochemical markers, RFLP, RAPD, synthetic oligo-nucleotide probes and SSRs have been used to assess genetic diversity and relationships.

\section{RFLP and RAPD markers}

Similar to that of the morphological and biochemical (isozyme) markers, RFLP and RAPD markers also show very low level of genetic variation between chickpea cultivars $[41,42]$. The low polymorphism may have been caused by narrow ancestry and self-pollinated nature of the crop [41]. Sant et al. [21] employed RAPD and oligo-nucleotide probes to assess genetic diversity between 29 elite Indian chickpea cultivars. Out of 35 RAPD primers tested, only 10 primers (29\%) generated polymorphic patterns between the cultivars, which indicate narrow genetic base of the cultivated species. The genetic distance values ranged from 0.09 to 0.27 based on RAPD analysis, whereas genetic distance ranged from 0.42 to 0.61 with oligo-nucleotide probes.

In another study, out of 78 RAPD primers tested, only 20 primers revealed polymorphisms between the chickpea cultivars [42]. Most of the RAPD polymorphisms appeared as single major band polymorphisms. The low degree of genetic variation detected by RFLP and RAPD markers in cultivated chickpea limit mapping of large number of these markers in a given cross.

\section{Oligo-nucleotide fingerprinting/ in-gel hybridization}

Oligo-nucleotide fingerprinting involves use of synthetic oligo-nucleotide probes complementary to microsatellites or Simple Sequence Repeats (SSRs) for in-gel or Southern hybridization with genomic DNA digested with individual restriction enzymes and electrophoresed on agarose gel. The probes can be designed without any sequencing efforts. Since repetitive DNA is present ubiquitously in all eukaryotic genomes [43], a large number of hybridizing fragments with varying sizes are generally obtained. These multi-locus probes may be useful for genetic characterization of cultivars and breeding lines, estimation of degree of relatedness and tagging of gene(s) of interest. If linkage with a gene is detected, sequence tagged microsatellites can be developed by sequencing the representative fragment, so that unique flanking sequences can be used as locus specific starting points for chromosome walking experiments [44].

Oligo-nucleotide probes representing microsatellites present as polymorphic repeats in the chickpea genome and detected intra as well as inter-specific variation in chickpea [44]. The number of hybridizing fragments varied between different probes and from species to species and the fingerprints are somatically stable.
According to Sant et al. [21] the genetic diversity among chickpea cultivars revealed by oligonucleotide fingerprinting is much higher as compared to RAPD markers. Since these probes yield more polymorphisms, few probes will be sufficient for thorough coverage of the genome, and show high reproducibility as compared to RAPDs. Therefore, these oligonucleotide probes may be useful for developing molecular markers and for gene introgression in a crop like chickpea with a narrow genetic base. However, the approach is limited with the following disadvantages:

a) Extensive clustering of simple sequence repeats.

b) High mutation rates leading to unexpected fragments (non-parental bands) in the progeny.

c) Dominant inheritance.

The occurrence of non-parental bands during linkage analysis may be minimized by the inclusion of parental and F1 DNAs in the segregation analysis and the preferred use of accession rather than individual specific probes [20].

\section{SSR markers}

The majority of the SSRs amplifies single loci with multiple alleles, and thus serves as viable alternative to synthetic oligonucleotide probes. The relatively simple interpretation and genetic analysis of single locus markers make them superior to multi-locus DNA markers, especially for map construction and DNA fingerprinting [45]. The ability of SSRs in detecting intra-specific variation in chickpea has been demonstrated by Huttel et al. [20]. Sixteen SSR loci detected 2-4 alleles at intraspecific level out of 22 loci tested. Two SSR loci, CaSTMS10 and CaSTMS15 detected 25 and 16 alleles, respectively, upon testing on a large number of chickpea accessions. Sethy et al. [46] used 25 polymorphic SSR markers to analyse intra-specific genetic diversity within 36 geographically diverse chickpea accessions. Based on cloning and sequencing of size variant alleles at two microsatellite loci revealed that the variable numbers of AG repeats in different alleles were the major source of polymorphism.

Further, Udupa et al. [47] studied dynamics of microsatellite evolution in chickpea and for this they selected di ant tri nucleotide repeat (TA) $n$ and (TAA) n, respectively, and based on polymorphism they observed that the two loci do not evolve in complete independence. Below a threshold level they evolve independently and above that threshold level if one allele increases in size the other closely linked locus decreases in its size and vice versa, without change in the overall ratio. Sethy et al. [48] cloned and sequenced microsatellite sequences from C. reticulatum and developed 11 SSR markers to analyse 29 accessions representing all nine annual Cicer species. Efficient marker transferability (97\%) of the C. reticulatum was observed as compared to microsatellite markers developed from cultivated species. Based on cluster analysis all the accessions (except two C. judaicum accessions) distinguished from one 
another and revealed intra and inter-species variability. An annual Cicer phylogeny was depicted which established higher similarity between C. arietinum and C. reticulatum. In the study placement of C. pinnatifidum in the second crossability group and its closeness to C. bijugum was supported. Two species C. yamashitae and C. chorassanicum were grouped distinctly and seemed to be genetically diverse from members of first crossability group. Recently, a large scale genetic diversity study in chickpea revealed detection of 1683 alleles in 2915 accessions from composite collections using 48 SSR markers and based on the molecular diversity deciphered a reference (core) set of 300 chickpea genotypes was constituted [49]. The above studies suggest that microsatellite markers are highly suitable for genome analysis in chickpea because of their rich allelic diversity and informativeness compared to other DNA markers.

\section{Genome Mapping and Gene Tagging Followed by Marker Assisted Selection}

Gaur \& Slinkard [50] developed the first rudimentary linkage map of Cicer, with 4 linkage groups consisting of 13 isozyme loci, although the linkage analysis among morphological traits were initiated an year earlier [51]. Three additional linkage groups were then established using both morphological and isozyme loci. With the advent of DNA markers, Cicer map was further expanded with 9 morphological, 28 isozyme, 44 RAPD, 9 RFLP and 6 other markers [52]. Currently existing map of Cicer consists of 354 various kinds of markers, approximately at an average distance of $6.8 \mathrm{cM}$ between markers [53], which is much higher than that of rice linkage maps comprising 2000 mapped molecular markers each approximately at every $0.9 \mathrm{cM}$ [54]. Many traits have not been mapped in the comprehensive map of Cicer except fusarium wilt resistance [53]. Hence, development of a high-density map with many morphological traits for Cicer must be the first step towards chickpea genomics. Such type of high-density molecular maps makes it feasible to identify, map and measure the effect of genes and gene blocks that contribute substantially to quantitative traits. Molecular markers have pronounced applications in indirect selection for linked traits like leaf rust resistance genes in wheat [55], fusarium wilt resistance in chickpea, accelerated backcrossing, analysis and selection of quantitative traits such as ascochyta blight in chickpea [56], identification of hybrids, selection for resistance to pests and pathogens not present in the immediate environment (quarantine traits) and the analysis of alien chromosome segments. Marker assisted breeding programs have been estimated to reduce the time-to-market by $50-70 \%$ [57]. Isolation of almost twenty R-genes from genetically wellcharacterized plant species has been facilitated because of molecular markers through map-based cloning over the past five years $[58,59]$. However, the use of markers to study genotype $\mathrm{X}$ environment interactions and to genetically dissect complex traits has gained enormous importance recently.

Another application of molecular markers is gene pyramiding which is mostly a resistance breeding procedure where more than one gene is brought together to enhance the resistance life of an otherwise better performing variety against the pathogenic races. Identification of markers for resistance genes can efficiently facilitate pyramiding major genes into a valuable background in less time and make it more cost effective. Gene pyramiding was successfully performed in apple for the scab and mildew resistance [59]. According to Jones [60], reported that pyramiding of $\mathrm{R}$ gene alleles from one species into a single genotype might not provide durable resistance, but will select pathogens that can tolerate the loss of multiple compatibility factors and may lead to yield penalties. Hence it is suggested that a population which is heterogeneous for different $\mathrm{R}$ genes have an advantage over a single cultivar with all $\mathrm{R}$ genes. In heterogeneous population, only a specific proportion of the plants can support the growth of any virulent race, so the rate of epidemic will be correspondingly reduced. The intense pathogen pressure of avirulent pathogen races may trigger systemic acquired resistance, which will reduce susceptibility to virulent races. Furthermore, any mutation affecting the virulence of a race that can overcome one $\mathrm{R}$ gene which enables it to grow on plants that have another $\mathrm{R}$ gene may result in slightly reduced parasite fitness against the first $\mathrm{R}$ gene. The heterogeneous population approach for developing resistance against pathogens can be attempted in chickpea to defend various fungal pathogens especially like Fusarium oxysporum in which different loci confer resistance to different races of this fungus and also Ascochyta rabiei [56], by the breeders.

Molecular Marker Assisted Selection (MAS) is based on the principle that if a gene (or block of genes) is tightly linked to an easily identifiable genetic marker it may be more efficient to select in a breeding programme for the marker than for the trait itself. The effectiveness of MAS depends on the strength of linkage between the marker and the gene locus controlling the trait of interest, and genetic control of the trait [61]. In case of single major gene, MAS can be the most effective means of transfer of the desired gene by backcross breeding. Isozymes and DNA markers have been widely used to tag gene(s) conferring resistance to various fungal, bacterial and viral diseases in different crop species and provide an opportunity to pyramid genes in various combinations. The molecular markers and their applications in plant breeding programmes have been reviewed extensively [62]. Various factors, including fungal inoculums levels and environmental conditions such as soil temperature and/or moisture level often influence disease development in field experiments. Molecular markers permit genotyping of individuals at seedling stage itself for the trait of interest in a disease-free environment. In chickpea, several genes conferring resistance to biotic stresses as well as agronomic traits have been tagged using molecular markers.

\section{Molecular markers in pathogen fingerprinting}

The pathogens of chickpea biotic stresses are generally soil or seed-borne and survive in soil up to 6 years even in the absence of the host plant [63]. The effectiveness of host resistance to the 
fungal pathogens is threatened by appearance of new pathogenic races that overcome resistance genes [64]. Therefore, it is highly desirable to determine the genetic variability existing within the pathogen population in order to breed chickpea cultivars with durable resistance. With the help of molecular markers there are different efforts had made on the most important pathogens of chickpea, such as fusarium wilt pathogen and ascochyta blight pathogen.

\section{Conclusion}

There are different genetic markers for evaluating genetic variation: morphological, biochemical and DNA markers. Morphological markers are a classical method to distinguish variation based on the observation of the external morphological differences (phenotypic characters) such as flower color, seed shape, growth habits or pigmentation although morphological markers are technically simple, they having several limitations. Biochemical and DNA markers are developed to overcome limitations of morphological data although it does not mean that any of the biochemical or molecular techniques or both replace morphological marker. Molecular markers have several advantages over morphological markers. Isoenzyme is popular biochemical markers that used in diversity analysis of different plants. Isoenzyme electrophoresis of chickpea had revealed insufficient polymorphism particularly in cultivated chickpea as a result of a narrow genetic variability.

Molecular markers such as SSR and SNP are useful for construction of high density genetic maps of chickpea. These maps will be useful in identification of genes/QTLs associated with stress resistance as well as quality traits for undertaking extensive molecular breeding in chickpea. Systematic pathogen surveys to identify new virulence and to get an insight into their regional distribution will help in devising appropriate management strategies for controlling important fungal diseases. Novel biotechnological approaches are required for introgression of useful traits from the wild Cicer species, a resource that is yet to be harnessed effectively.

\section{References}

1. Gupta P (2003) Elements of Biotechnology. Rostig publication, India.

2. Hunter M (1996) Fundamentals of Conservation Biology. Blackwell Science, Inc., USA.

3. Winter P (1997) Development and use of molecular markers for chickpea improvement. In: DNA Markers and Breeding for Resistance to Ascochyta Blight in Chickpea. Proceedings of the symposium on "Application of DNA Fingerprinting for Crop Improvement: Marker Assisted Selection of Chickpea for Sustainable Agriculture in the Dry Areas," pp. 155-174, (S. M. Udupa and F. Weigand, eds.).

4. Lee M (1995) DNA markers and plant breeding programs. Adv in agron 55: 265-344.

5. Jodha NS, Subba Rao KV (1986) Chickpea: World Importance and Distribution. In: Saxena MC, Singh KB (1987) The chickpea, CAB international, Wallingford, UK.
6. Singh O, Paroda RS (1986) Association of grain yield and its components in chickpea following hybridization and a combination of hybridization and mutagenesis. Indian J Agric Sci 56(2): 139-141.

7. Gwanme C, Labuschangne MJ, Botha AM (2000) Analysis of genetic variation in Cucurbita moschata by random amplified polymorphic DNA (RAPD) Markers. Euphytica 113(1): 19-24.

8. Vienne DD, Santoni S, Falque M (2003) Principal sources of molecular markers. In: Vienne DD (ed.). Molecular Markers in Plant Genetics and Biotechnology. Science Publishers, Inc., Plymouth, UK. pp 3-41.

9. Dulloo ME, Guarino L, Ford-Lioyed BV (1997) A bibliography and a review of genetic diversity studies of African germplasm using protein and DNA Markers. Genetic Reso Crop evol 44: 447-470.

10. Feven W (2002) Morphological and biochemical diversity analysis in chickpea (Cicer arietinum L. Fabaceae) landraces of Ethiopia. M.Sc. thesis submitted to Addis Ababa University, Addis Ababa, Ethiopia.

11. Mengesha MH (1975) Crop germplasm diversity resources of Ethiopia. In: Frankel OH, Hawkes JG (eds.). Campridge Univ Press, Cambridge. pp 449-453

12. Kumar J, Bahl PN, Mehra RBN, Raju DB (1981 Variability in chickpea. International Chickpea Newsletter 5: 3-4.

13. Van Der Maesen LJG (1987) Origin, history and taxonomy of chickpea. In: The Chickpea. Eds. Saxena, MJ and Singh KB pp 11-34. CAB International, Cambridge.

14. Adhikari G, Pandey MP (1982) Genetic variability in some quantitative characters and scope for improvement in chickpea. International Chickpea Newsletter 7: 4-5.

15. Khorgade PW, Narkhede MN, Raut SK (1985) Genetic variability studies in chickpea. International Chickpea Newsletter 12:12-13.

16. Misra RC (1991) Stability of heritability, genetic advance and character association estimates in chickpea. International Chickpea Newsletter 25: 10-11.

17. Pandey RL, Tawari AS (1983) Heritability and genetic gain in chickpea. International Chickpea Newsletter 9: 5-6.

18. Hadjichristoudoulou A (1987) Associations between traits of chickpea varieties. International Chickpea Newsletter 17: 2-4.

19. Dahiya BS, Waldia RS, Tomer YS (1980) Basis of selection in chickpea. International Chickpea Newsletter 3: 6 .

20. Sharman PC, Winter P, Bunger T, Huttel B, Kahl G (1997) Expanding the repertoire of molecular markers for resistance breeding in chickpea. In: DNA Markers and Breeding for Resistance to Ascochyta Blight in Chickpea. Proceedings of the symposium on "Application of DNA Fingerprinting for Crop Improvement of: Marker Assisted Selection of Chickpea for Sustainable Agriculture in the Dry Areas," pp. 175-198, (S. M. Udupa and F. Weigand, eds.). 11-12 April 1994, Aleppo, Syria/ ICARDA, Aleppo, Syria.

21. Sant VJ, Patankar AG, Sarode ND, Mhase LB, Sainani MN, et al. (1999) Potential DNA markers in detecting divergence and in analyzing heterosis in Indian elite chickpea cultivars. Theo App Gene 98(8): 12171225.

22. Tanksley SD, Rick CM (1980) Isozymic gene linkage map of the tomato: Applications in genetics and breeding. Theor Appl Genet 57: 161-70.

23. Schaal BA, Leverich WJ, Rogstad SH (1991) A comparison of methods for assessing genetic variation in plant conservation biology. In: Genetics and Conservation of Rare Plants, pp.123 -134, (D.A. Falk and K. E. Holsinger, eds), Oxford University Press, UK.

24. Kazan K, Muehlbauer FJ, Weeden NF, Ladizinsky G (1993) Inheritance and linkage relationships of morphological and isozyme loci in chickpea (Cicer arietinum L.). Theor App Gen 86(4): 417-426. 
25. Samec P, Nasinec V (1996) The use of RAPD techniques for identification and classification of Pisum sativum L. genotypes. Euphytica 89(2): 229-234.

26. Margal'e E, herv'e Y, Hu J, Quiros CF (1995) Determination of genetic variability by RAPD markers in cauliflower, cabbage, and Kale local cultivars from France. Genetic Reso Crop Evol 42(3): 281-289.

27. Ayana A, Bekele (E 1999) Multivariate analysis of morphological variation in sorghum (Sorghum bicolor ssp. verticilliforum (L) Moench) germplasm from Ethiopia and Eritrea. Genet Reso crop evol 46: 273-284.

28. Birmata G, Nybom H, Bekele E (2004) Distinction between wild and cultivated enset (Ensete ventricosum) gene pools in Ethiopia using RAPD markers. Hereditas 140(2): 139-148.

29. Ahmad F (1999) Random Amplified polymorphic DNA (RAPD) analysis reveals genetic relationships among the annual Cicer species. Theo Appl Genet 98(3-4): 657-663.

30. Hadrys H, Balcik M, Schierwater B (1992) Applications of random amplified polymorphic DNA (RAPD) in molecular ecology. Mol Ecol 1(1): 55-63.

31. Gepts P (1995) Genetic markers and core collection. In: Hodgkin J, Brown AHD, Van JL, Hintum, Morales AV (eds.), John Wiley and Sons, Chirchester pp. 127-147.

32. Ruiz M, Varela F, Carillo JM (1997) Analysis of the discriminating power of agro/morphological and biochemical descriptors in the sample of the Spanish collection of barely (Hordeum Vulgare L.). Gene Rreso Crop Evol 44: 247-255.

33. Labdi M, Robertson LD, Singh KB, Charrier (1996) A genetic diversity and phylogenetic relationships among the annual Cicer species as revealed by isozyme polymorphism. Euphytica 88(3): 181-188.

34. Smith OS, Smith JSC, Bowen SL, Tenborg RA, Wall SJ (1990) Similarities among a group of elite maize inbreds as measured by pedigree $\mathrm{F} 1$ grain yield, heterosis and RFLPs. Theor Appl Genet 80(6): 833-840.

35. Leonardi A, Damerval C, Hebert Y, Gallais A, De Vienne D (1991) Association of protein amount polymorphic (PAP) among maize lines with performances of their hybrids. Theor Appl Genet 82(5): 552-560.

36. Ahmad F, Slinkard AE (1992) Genetic relationships in the genus Cicer L. as revealed by polyacrylamide gel electrophoresis of seed storage proteins. Theor Appl Genet 84(5-6): 688-692.

37. Tayyar RI, Waines JG (1996) Genetic relationships among annual species of Cicer (Fabaceae) using isozyme variation. Theor Appl Genet 92(2): 245-254.

38. Patil P, Vrinten PL, Scoles GJ, Slinkard AE (1995) Variation in the ribosomal RNA units of the genera Lens and Cicer. Euphytica 83(1): 33-42.

39. Udupa SM, Robertson LD, Weigand F, Baum M, Kahl G (1999) Allelic variation at (TAA)n microsatellite loci in a world collection of chickpea (Cicer arietinum L.) germplasm. Mol Gen Genet 261(2): 354-363.

40. Choumane W, Winter P, Weigand F, Kahl G (2000) Conservation and variability of sequence tagged microsatellite sites (STMS) from chickpea (Cicer arietinum L.) within the genus Cicer. Theor Appl Genet 101:269-278.

41. Van Rheenen HA (1992) Biotechnology and chickpea breeding. International Chickpea Newsletter 26: 14-17.

42. Singh R, Durga Prasa C, Singhal V, Randhawa GJ (2003) Assessment of genetic diversity in chickpea cultivars using RAPD, AFLP and STMS markers. Journal of Genetics and Breeding 57: 165-174.

43. Tautz D (1989) Hypervariability of simple sequences as a general source for polymorphic DNA markers. Nucleic Acids Research 17(16): 6463-6471.
44. Weising M, Kaemmer D, WeigandJ F, Epp len T, G.ahl K (1992) Oligonucleotide fingerprinting reveals various probe-dependent levels of informativeness in chickpea (Cicer arietinum). Genome 35(3): 436-442.

45. Thomas MR, Scott NS (1993) Microsatellite repeats in grapevine reveal DNA polymorphisms when analysed as sequence-tagged sites (STSs) Theor Appl Genet 86(8): 985-990.

46. Sethy NK, Choudhar YS, Shokeen B, Bhatia S (2006a) Identification of microsatellite markers from Cicer reticulatum; molecular variation and phylogenetic analysis. Theor Appl Genet 112(2): 347-357.

47. Udupa SM, Malhotra RS, Baum M (2004) Tightly linked di- and trinucleotide microsatellites do not evolve in complete independence: evidence from linked (TA)n and (TAA)n microsatellites of chickpea (Cicer arietinum L.). Theor Appl Genet 108: 550-557.

48. Sethy NK, Shokeen B, Edwar ds K.J, Bhatia S (2006b) Development of microsatellite markers and analysis of intraspecific genetic variability in chickpea (Cicer arietinum L.). Theor Appl Genet 112(8): 1416-1428.

49. Upadhyaya HD, Dwivedi SL, Baum M, Varsheny RK, Udupa SM, et al. (2008) Genetic structure, diversity, and allelic richness in composite collection and reference set in chickpea (Cicer arietinum L.). BMC Plant Biol 8: 106 .

50. Gaur PM, Slinkard AE (1988) Inheritance and linkage relationships of some isozyme loci in Cicer. Genome 30: 243.

51. Muehlbauer FJ, Singh KB (1987) Genetics of chickpea. In: Saxena MC Singh KB (Eds.) The chickpea, CAB International, Wallingford, Oxon, UK.

52. Simon CJ, Muehlbauer FJ (1997) Construction of a chickpea linkage map and its comparison with maps of pea and lentil. J Hered 88(2): 115-119.

53. Winter P, Benko-Iseppon B, Huttel M, Ratnaparkhe A, Tullu G, et al. (2000) A linkage map of the chickpea (Cicer arietinum L.) genome based on recombinant inbred lines from a $C$. arietinum X C. reticulatum cross: localization of resistance genes for fusarium wilt races 4 and 5 . Theor Appl Genet 101(7): 1155-1163.

54. Kurata N, Nagamura Y (1994) A 300kb interval genetic map of rice including 883 expressed Kusm enoglu, I., F.J. Muehlbauer, And K. Kaza $\mathrm{n}, 1992$. Inheritance of isozyme variation in sequences. Nat Genet 8: 365-372.

55. Feuillet C, Schachermayer G, Keller B (1997) Molecular cloning of a new receptor like kinase gene encoded at $\operatorname{Lr} 10$ disease resistance locus of wheat. Plant J 11(1): 45-52.

56. Santra DK, Tekeoglu M, Ratnaparkhe MB, Gupta VS, Ranjekar PK, et al. (2000) Identification and Mapping of QTLs conferring Resistance to Ascochyta Blight in Chickpea. Crop Sci 40(6): 1606-1612.

57. Schneider (1997) Marker-assisted selection to improve drought resistance in common bean. Crop Sci 37(1): 51-60.

58. Martin GB (1999) Functional analysis of plant disease resistance genes and their downstream effectors. Curr Opin Plant Biol 2(4): 273-279.

59. Tartarini S, Gianfranceschi L, Sansavini S, Gessler C (1999) Development of reliable PCR markers for the selection of the $V f$ gene conferring scab resistance in apple. Plant Breed 118(2): 183-186.

60. Jones JD (2001) Putting knowledge of plant disease resistance genes to work. Current Opin Plant Biol 4(4): 282-287.

61. Haywar MD, Mcadam NJ, Jones JG, Evans C, Evans GM, et al. (1994) Genetic markers and the selection of quantitative traits in forage grasses. Euphytica 77(3): 269-275.

62. Gupta PK, Varshney RK, Sharma PC, Ramesh B (1999) Molecular markers and their applications in wheat breeding. Plant Breeding 118(5): 369-390. 
63. Haware MP, Nene YL, Natarajan M (1996) Survival of Fusarium oxysporum f. sp. ciceri in soil in the absence of chickpea. Phytopathologie Mediterranea 35(1): 9-12.
64. Kaiser WJ, Alca la-jimenez AR, Hervas -Var gas A, Trap ero-casas JI, Jimenez-diaz RM (1994) Screening of wild cicer species for resistance to races 0 and 5 of Fusarium oxysporum f.sp. ciceris. Plant Diseases 78 : 962-967.

\section{Your next submission with Juniper Publishers will reach you the below assets}

- Quality Editorial service

- Swift Peer Review

- Reprints availability

- E-prints Service

- Manuscript Podcast for convenient understanding

- Global attainment for your research

- Manuscript accessibility in different formats ( Pdf, E-pub, Full Text, Audio)

- Unceasing customer service

Track the below URL for one-step submission https://juniperpublishers.com/online-submission.php 